\title{
The Impact of Power Structures and Pricing Methods on the Performance of Dual-Channel Low-Carbon Supply Chains
}

\author{
Jing Hu \\ Logistics Research Center, Shanghai Maritime University, Shanghai, China \\ Email: jinghu550@163.com
}

How to cite this paper: Hu, J. (2020). The Impact of Power Structures and Pricing Methods on the Performance of Dual-Channel Low-Carbon Supply Chains. Open Journal of Business and Management, 8, 2303-2316. https://doi.org/10.4236/ojbm.2020.85141

Received: August 24, 2020

Accepted: September 27, 2020

Published: September 30, 2020

Copyright ( 2020 by author(s) and Scientific Research Publishing Inc. This work is licensed under the Creative Commons Attribution International License (CC BY 4.0).

http://creativecommons.org/licenses/by/4.0/

\begin{abstract}
This paper considers a secondary low-carbon supply chain consisting of one manufacturer and one dual-channel retailer. The four game models of retailer in the two-channel unified pricing and separate pricing and the two power structures dominated by manufacturer and retailer are constructed. The paper analyzes and compares the choice of retailer pricing methods under the same power structure and the optimal decision of supply chain members under different power structures. Research shows that a retailer is more willing to choose separate pricing under the same power structure, and pricing methods have no effect on the manufacturer. Under different power structures, retailer gains more when he leads the supply chain. For the manufacturer, when the carbon emission reduction investment cost coefficient is small (large), manufacturer gains more when retailer (self) dominates.
\end{abstract}

\section{Keywords}

Power Structure, Carbon Emission Reduction, Retailer Dual Channel, Low Carbon Supply Chain

\section{Introduction}

With the rapid development of the global economy, the continuous increase in greenhouse gas emissions has caused a huge impact on our society and the environment. Global climate change has created a huge threat to human survival and health (Ma, 2019). China is the world's largest carbon dioxide emitter. Therefore, more and more manufacturers begin to produce low-carbon products, such as Gree, Midea and other home appliance companies investing in carbon emission reduction technology to produce fluorine-free air conditioners, and Tesla 
and other automakers are developing new energy vehicles. On the other hand, the development of e-commerce has led many retailers to open up online channels, such as Suning, Gome, Carrefour and Wal-Mart. IKEA, which has always insisted on offline sales, also launched a small program called "IKEA Pop-up Store" in 2018. For retailers who have developed dual channels, whether direct channels and retail channels are priced uniformly is a key issue. In addition, due to the different resources occupied by supply chain members, different power structures exist, for example, Wal-Mart, a retailer with a strong advantage in the supply chain, and Procter \& Gamble, a large manufacturer. Both power structure and pricing methods have an impact on supply chain performance.

Three areas are related to the research in this article. One is the dual-channel low-carbon supply chain. Xu et al. (2018) considered the coordination of the manufacturer's dual-channel supply chain under mandatory carbon emission control. Ji et al. (2017) considered the emission reduction behavior and channel selection of supply chain members in the case of only retail channels and dual channels under the factors of carbon allowance and consumers' low-carbon preference. Yang et al. (2018) studied the remanufacturing problem in the manufacturer's dual-channel supply chain, as well as the optimal emission reduction level and pricing strategy of carbon emissions on the basis of carbon allowances. Ranjan and Jha (2019) studied the pricing strategy and coordination mechanism between members in a dual-channel supply chain. Wang et al. (2016) studied channel selection and pricing strategies in the supply chain, which includes a leading multi-channel retailer and a manufacturer that sells two levels of differentiated products through direct channels and retail channels. Liu et al. (2019) studied the channel selection and channel cooperation strategy issues of low-carbon emission reduction manufacturer. Yu et al. (2019) studied the impact of consumers' low-carbon preference differences on manufacturer' dual-channel supply chain pricing strategies. Yang et al. (2017) studied the channel selection and coordination of the dual-channel low-carbon supply chain led by manufacturers. Sun (2018) and others studied low-carbon supply chain emission reduction strategies that consider consumer channel preferences and low-carbon preferences. The above research on dual-channel low-carbon supply chain mainly focuses on channel selection, coordination and pricing strategies, and does not involve power structure issues.

The second is the power structure. Chen and Wang (2015) take the smartphone supply chain composed of mobile phone manufacturers and telecom service operators as the research object. The optimal retail price decision of manufacturers in free and bundling channels under different power structures and the optimal subsidy decision of telecommunication service operators in bundling channels are studied. Luo et al. (2018) studied the influence of different power structures on supply chain pricing decisions. Jin (2018) studied the impact of different power structures on retailer' dual-channel supply chain equilibrium and consumer surplus. The research results show that the different power struc- 
tures of the suppliers will not affect the overall profit and consumer surplus of the supply chain, but only lead to the redistribution of revenue within the supply chain system. Lan Tian (2018) studied the impact of different power structures on supply chain pricing and brand differentiation strategies from the perspective of supply chain and consumer surplus. Yang Yan (2019) and others have studied the influence of different power institutions on suppliers' fulfillment of social responsibilities. The study found that compared with the supplier's leadership, the supplier will perform more social responsibilities under the retailer's leadership. Wang et al. (2017) studied the influence of power structure on the prices, demand and profits of dual-channel supply chain members. Scholars at home and abroad have done a lot of research on the power structure of single-channel and dual-channel, but they have not considered the influence of power structure and pricing method on low-carbon supply chain.

The third is a dual-channel supply chain pricing method. Li et al. (2016) discussed the pricing strategy of supply chain members under centralized and decentralized decision-making under the manufacturer's dual-channel unified pricing. Yang and Xiao (2017) discussed the channel selection and coordination issues under the dual-channel unified pricing of manufacturers. Liang et al. (2018) discussed the pricing strategy and channel selection of manufacturers under dual-channel separate pricing. Zhou et al. (2017) discussed the supply chain emission reduction and pricing decisions considering the dual-channel separate pricing of carbon allowance retailer. Zhang et al. (2018) studied the manufacturer's dual-channel supply chain pricing decision considering the risk of return. Research shows that retailer prefers a dual-channel unified pricing model, while manufacturer prefers a separate pricing model. There are few literatures on pricing methods, and there is no comprehensive consideration of power structure and low-carbon supply chain. Therefore, this article takes the retailer's dual-channel low-carbon secondary supply chain as the research object, considers consumers' low-carbon preferences and channel preferences, and studies the impact of pricing methods and power structures on the performance of supply chain members. This article will enrich the research of retailer's dual-channel low-carbon supply chain.

The rest of this paper is organized as follows. The model description is reviewed in Section 2. Section 3 presents the models. Section 4 explores the changes in the benefits of supply chain members under different pricing methods and different power structures. Section 5 presents conclusions and future research direction.

\section{Model Description}

This article mainly studies the impact of different supply chain power structures and pricing methods on the performance of supply chain members. We consider a secondary low-carbon supply chain (Incorporate green, low-carbon, and environmentally friendly concepts and technologies into the supply chain) consisting 
of a manufacturer and a retailer. Manufacturer sells a single low-carbon product, and retailer order products from the manufacturer and then sell low-carbon products through dual channels. The related parameter definitions and decision variables are shown in Table 1 and Table 2.

Basic assumptions:

1) According to relevant literature, assume that the cost of carbon reduction and emission reduction invested by the manufacturer in retail channel is $\frac{1}{2} k\left(e_{r}\right)^{2}$ and the cost of carbon reduction and emission reduction invested in direct channel is $\frac{1}{2} k\left(e_{d}\right)^{2}$.

2) The demand for low-carbon products is determined by the sales price and carbon emission reduction level. Under unified pricing, the demand functions of low-carbon products in retail channel and direct channel are respectively:

$$
\left\{\begin{array}{l}
q_{r}=\theta a+\lambda e_{r}-b p \\
q_{d}=(1-\theta) a+\lambda e_{d}-b p
\end{array}\right.
$$

the demand function under separate pricing is

$$
\left\{\begin{array}{l}
q_{r}=\theta a+\lambda e_{r}-p_{r}+b p_{d} \\
q_{d}=(1-\theta) a+\lambda e_{d}-p_{d}+b p_{r}
\end{array}\right.
$$

\begin{tabular}{|c|c|}
\hline Parameters & definition \\
\hline$a$ & market demand \\
\hline$\lambda$ & consumer low-carbon preference $(\lambda>0)$ \\
\hline$c$ & unit production cost \\
\hline$b$ & cross price sensitivity coefficient $(b \in[0,1]$ ) \\
\hline$k$ & carbon emission reduction investment cost coefficient $(k>0)$ \\
\hline$q_{r}, q_{d}$ & retail channel and direct channel order volume \\
\hline$\theta, 1-\theta$ & Consumers' preference for retail and direct channel $(\theta \in[0,1])$ \\
\hline$\prod_{m}^{i}, \prod_{r}^{i}, \prod_{C}^{i}$ & $\begin{array}{l}\text { The revenue of manufacturer, retailer and supply chain in scenario } i \text {, } \\
\text { where } i=R S T, R S F, M S T, M S F \quad \text { (The superscript RS means retailer-led, MS } \\
\text { means manufacturer-led, T means unified pricing, and F means separate pricing) }\end{array}$ \\
\hline
\end{tabular}

Table 1. Parameters.

Table 2. Decision variables.

\begin{tabular}{cl}
\hline Decision variables & \multicolumn{1}{c}{ definition } \\
\hline$p$ & Retailer's unit product sales price when dual-channel unified pricing \\
$p_{r}, p_{d}$ & $\begin{array}{l}\text { Prices of retail channel and direct channel when dual-channel separated } \\
\text { pricing }\end{array}$ \\
$w$ & Unit product wholesale price \\
$e_{r}, e_{d}$ & Carbon emission reduction levels in retail channel and direct channel
\end{tabular}


3) To ensure that the objective function is the concave function of the decision variable and that the decision variable is greater than 0 , assume that $k>\lambda^{2} /[2(1-b)], a>2(1-b) c$.

4) $p>w>c$.In order to ensure the profits of retailer and manufacturer, the unit product sales price must be higher than the wholesale price, which is higher than the production cost.

5) The information between the manufacturer and the retailer is symmetrical and completely rational, pursuing the maximization of their own interests respectively. And consumers understand their carbon emission reduction levels before buying products.

\section{Models}

Based on the above assumptions, the revenue function of manufacturer and retailer under uniform pricing is: $\prod_{r}^{i}=(p-w)\left(q_{d}+q_{r}\right)$,

$\Pi_{m}^{i}=(w-c)\left(q_{d}+q_{r}\right)-\frac{1}{2} k\left(e_{d}\right)^{2}-\frac{1}{2} k\left(e_{r}\right)^{2}$. The superscripts "RST" and "MST" respectively denote a dual-channel low-carbon supply chain led by retailers and manufacturers under uniform pricing.

The revenue function of the manufacturer and retailer under separate pricing is: $\prod_{r}^{i}=\left(p_{r}-w\right) q_{r}+\left(p_{d}-w\right) q_{d}, \quad \prod_{m}^{i}=(w-c)\left(q_{d}+q_{r}\right)-\frac{1}{2} k\left(e_{d}\right)^{2}-\frac{1}{2} k\left(e_{r}\right)^{2}$. The superscripts " $R S T$ " and "MST" respectively denote a dual-channel low-carbon supply chain led by retailers and manufacturers under separate pricing.

\subsection{Supply Chain Led by Retailer (RS)}

When the retailer takes the lead, the retailer is the leader of the supply chain and the manufacturer is the follower. Retailers have the leading power and first decision-making power over the supply chain. The decision sequence is shown in Figure 1.

\subsubsection{Retailer Unified Pricing}

This game is a Stackelberg game with complete information, which is solved by reverse induction. To $m$ represent the retailer's marginal profit, the retail price of the product is $p^{R S T}=w^{R S T}+m$. Substitute Formula (1) and Formula (2) into $\prod_{m}^{R S T}$ and set $\partial \prod_{m}^{R S T} / \partial w^{R S T}=0$. The relationship between $w^{R S T}$ and $e_{r}^{R S T}, e_{d}^{R S T}$ is: $\quad w^{R S T}=\left[a+2(1-b)(c-m)+\left(e_{d}^{R S T}+e_{r}^{R S T}\right) \lambda\right] /[4(1-b)]$. Substituting Formula (1), Formula (2), $w^{R S T}$ into $\prod_{m}^{R S T}$, the Hessian matrix:

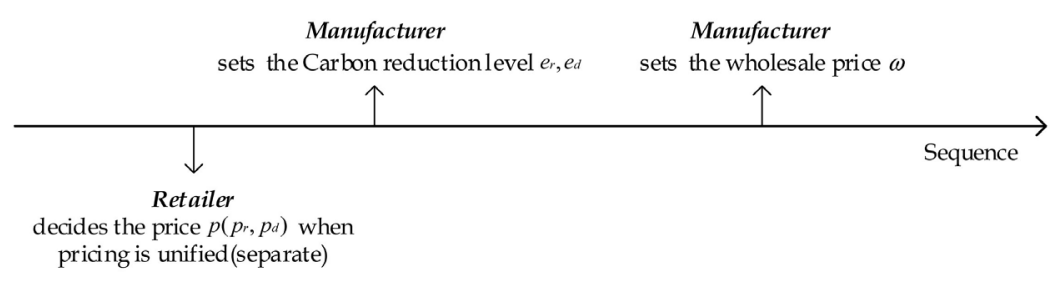

Figure 1. Sequence of events when retailer dominates the supply chain (RST/RSF). 


$$
H^{R S T}=\left|\begin{array}{cc}
\frac{\partial^{2} \prod_{m}^{R S T}}{\partial^{2} e_{r}^{R S T}} & \frac{\partial^{2} \prod_{m}^{R S T}}{\partial e_{r}^{R S T} \partial e_{d}^{R S T}} \\
\frac{\partial^{2} \prod_{m}^{R S T}}{\partial e_{d}^{R S T} \partial e_{r}^{R S T}} & \frac{\partial^{2} \prod_{m}^{R S T}}{\partial^{2} e_{d}^{R S T}}
\end{array}\right|=\frac{k\left[2(1-b) k-\lambda^{2}\right]}{2(1-b)}>0 .
$$

In addition, $\partial^{2} \prod_{m}^{R S T} / \partial^{2} e_{r}^{R S T}<0$. That is, the Hessian matrix $H^{R S T}$ is negative definite and has a maximum value. Respectively find the first derivative of $e_{r}^{R S T}, e_{d}^{R S T}$, set $\partial \prod_{m}^{R S T} / \partial e_{r}^{R S T}=0$ and $\partial \prod_{m}^{R S T} / \partial e_{d}^{R S T}=0$, and solve these two equations simultaneously, $e_{r}^{R S T}=e_{d}^{R S T}=[a-2(1-b)(c+m)] \lambda /\left[4(1-b) k-2 \lambda^{2}\right]$.

Substituting $e_{r}^{R S T}, e_{d}^{R S T}$ into formula $w^{R S T}$, subtracting $e_{r}^{R S T}, e_{d}^{R S T}$, we get:

$$
w^{R S T}=c+k[a-2(1-b)(c+m)] /\left[4(1-b) k-2 \lambda^{2}\right] .
$$

Substituting formula $e_{r}^{R S T}, e_{d}^{R S T}$ and formula $w^{R S T}$ into Formula (1) and Formula (2), we get:

$$
\begin{aligned}
q_{r}^{R S T} & =\frac{-(1-b)[a+2(1-b)(c+m)-4 a \theta] k+a(1-2 \theta) \lambda^{2}}{4(1-b) k-2 \lambda^{2}} q_{d}^{R S T} \\
& =\frac{-2(1-b)^{2}(c+m) k+a(1-b)(3-4 \theta) k-a(1-2 \theta) \lambda^{2}}{4(1-b) k-2 \lambda^{2}}
\end{aligned}
$$

Substituting $e_{r}^{R S T}, e_{d}^{R S T}$, formula $w^{R S T}$, into $\prod_{r}^{R S T}, q_{r}^{R S T}, q_{d}^{R S T}$ and finding the first derivative of $m$, so that $\partial \prod_{r}^{R S T} / \partial m=0$ gives: $m=[a-2(1-b) c] /[4(1-b)]$.

Substituting $m=[a-2(1-b) c] /[4(1-b)]$ into $w^{R S T}, e_{r}^{R S T}, e_{d}^{R S T}, q_{r}^{R S T}, q_{d}^{R S T}$, the optimal decisions are:

$$
\begin{aligned}
w^{R S T^{*}} & =c+[a-2(1-b) c] k /\left[8(1-b) k-4 \lambda^{2}\right], \\
e_{r}^{R S T^{*}} & =e_{d}^{R S T^{*}}=[a-2(1-b) c] \lambda /\left[8(1-b) k-4 \lambda^{2}\right], \\
q_{r}^{R S T^{*}} & =\frac{1}{4}\left(2 a(-1+2 \theta)+\frac{(1-b)[a-2(1-b) c] k}{2(1-b) k-\lambda^{2}}\right), \\
q_{d}^{R S T^{*}} & =\frac{1}{4}\left(2 a(1-2 \theta)+\frac{(1-b)[a-2(1-b) c] k}{2(1-b) k-\lambda^{2}}\right) .
\end{aligned}
$$

Then get

$$
p^{R S T^{*}}=\frac{1}{4}\left(\frac{a}{1-b}+2 c+\frac{[a-2(1-b) c] k}{2(1-b) k-\lambda^{2}}\right) .
$$

From this, the revenue of retailer and manufacturer under the retailer-led and unified pricing is: $\prod_{m}^{R S T^{*}}=[a-2(1-b) c]^{2} k /\left[32(1-b) k-16 \lambda^{2}\right]$, $\prod_{r}^{R S T^{*}}=[a-2(1-b) c]^{2} k /\left[16(1-b) k-8 \lambda^{2}\right]$.

The benefit of the supply chain is: $\prod_{C}^{R S T^{*}}=3[a-2(1-b) c]^{2} k /\left[32(1-b) k-16 \lambda^{2}\right]$.

\subsubsection{Retailer Separate Pricing}

Let represents the marginal profit of the retailer's retail channel and direct 
channel, the retail channel price of the product is, and the direct channel price is $p_{d}^{R S F}=w^{R S T}+m_{2}$. Same as the solution method in 3.1.1, we get the optimal decision and benefit under retail-led separate pricing:

$$
\begin{aligned}
& e_{r}^{R S F^{*}}=e_{d}^{R S F^{*}}=[a-2(1-b) c] \lambda /\left[8(1-b) k-2 \lambda^{2}\right] \\
& w^{R S F^{*}}=\left[a k+6(1-b) c k-4 c \lambda^{2}\right] / 4\left[2(1-b) k-\lambda^{2}\right] \\
& \left\{\begin{array}{l}
p_{r}^{R S F^{*}}=\frac{c\left(1-b^{2}\right)+a(b+\theta(1-b))}{2\left(1-b^{2}\right)}+\frac{[a-2(1-b) c] k}{4\left[2(1-b) k-\lambda^{2}\right]} \\
p_{d}^{R S F^{*}}=\frac{c\left(1-b^{2}\right)+a[1-\theta(1-b)]}{2\left(1-b^{2}\right)}+\frac{[a-2(1-b) c] k}{4\left[2(1-b) k-\lambda^{2}\right]}
\end{array}\right. \\
& \left\{\begin{array}{l}
q_{r}^{R S F^{*}}=\frac{-(1-b) k(2(1-b) c+a(1-4 \theta))+a(1-2 \theta) \lambda^{2}}{4\left[2(1-b) k-\lambda^{2}\right]} \\
q_{d}^{R S F^{*}}=\frac{(1-b) k[-2(1-b) c+a(3-4 \theta)]-a(1-2 \theta) \lambda^{2}}{4\left[2(1-b) k-\lambda^{2}\right]}
\end{array}\right.
\end{aligned}
$$

The optimal benefits of retailer and manufacturer under the retailer-led and unified pricing are:

$$
\prod_{m}^{R S F^{*}}=\frac{[a-2(1-b) c]^{2} k}{16\left[2(1-b) k-\lambda^{2}\right]}, \prod_{r}^{R S F^{*}}=\frac{a^{2}(1-2 \theta)^{2}}{8(1+b)}+\frac{[a-2(1-b) c]^{2} k}{8\left(2(1-b) k-\lambda^{2}\right)}
$$

The total revenue of the supply chain is:

$$
\Pi_{c}^{R S F^{*}}=\frac{a^{2}(1-2 \theta)^{2}}{8(1+b)}+\frac{3[a-2(1-b) c]^{2} k}{16\left[2(1-b) k-\lambda^{2}\right]}
$$

\subsection{Supply Chain Led by Manufacturer (MS)}

When the manufacturer takes the lead, the manufacturer is the leader of the supply chain and the retailer is the follower. Manufacturers have the leadership and first decision-making power over the supply chain. The decision sequence is shown in Figure 2.

\subsubsection{Uniform Pricing}

Solve by reverse induction. Substituting Formula (1) and Formula (2) into the retailer's revenue, the reaction function of the retailer's sales price $p^{M S T}$ to

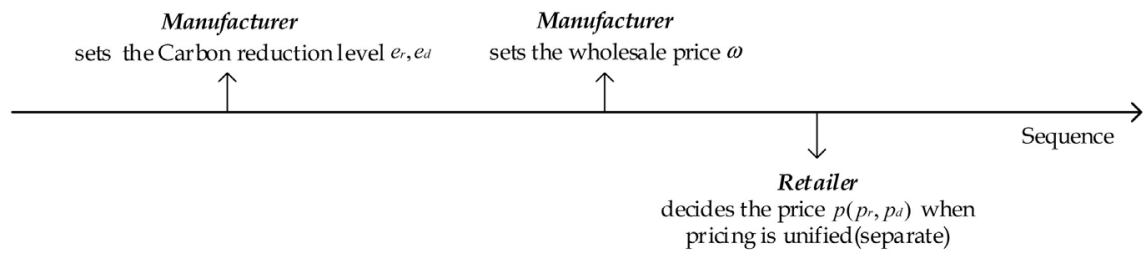

Figure 2. Sequence of events when manufacturer dominates the supply chain (MST/MSF). 
$e_{r}^{M S T}, e_{d}^{M S T}, w^{M S T}$ is: $\quad p^{M S T}=\left[a+\left(e_{d}^{M S T}+e_{r}^{M S T}\right) \lambda+2(1-b) w^{M S T}\right] / 4(1-b)$. Substitute equation $p^{M S T}$ into Equations (1) (2), and eliminate $p^{M S T}$. The reaction function of order quantity $q_{r}^{M S T}, q_{d}^{M S T}$ to $e_{r}^{M S T}, e_{d}^{M S T}, w^{M S T}$ is:

$$
q_{r}^{M S T}=\left[\lambda\left(3 e_{r}^{M S T}-e_{d}^{M S T}\right)-a(1-4 \theta)-2(1-b) w^{M S T}\right] / 4
$$

and

$$
q_{d}^{M S T}=\left[a(3-4 \theta)+\lambda\left(3 e_{d}^{M S T}-e_{r}^{M S T}\right)-2(1-b) w^{M S T}\right] / 4 ;
$$

Substituting $q_{r}^{\text {MST }}$ and $q_{d}^{\text {MST }}$ into the manufacturer's income, Let $\partial \prod_{m}^{M S T} / \partial w^{M S T}=0$, the reaction function of $w^{M S T}$ to $e_{r}^{M S T}, e_{d}^{M S T}$ is:

$$
w^{M S T}=\left[a+2(1-b) c+\left(e_{d}^{M S T}+e_{r}^{M S T}\right) \lambda\right] / e_{d}^{M S T}+e_{r}^{M S T} .
$$

Substitute $w^{M S T}$ into $p^{M S T}, q_{r}^{M S T}, q_{d}^{M S T}$ and eliminate $w^{M S T}$. The reaction function of $q_{r}^{M S T}, q_{d}^{M S T}, p^{M S T}$ to $e_{r}^{M S T}, e_{d}^{M S T}$ is:

$$
\begin{gathered}
q_{r}^{\text {MST }}=\left[-2(1-b) c-a(3-8 \theta)-3 e_{d}^{M S T} \lambda+5 e_{r}^{M S T} \lambda\right] / 8, \\
q_{d}^{M S T}=\left[-2(1-b) c+a(5-8 \theta)+5 e_{d}^{M S T} \lambda-3 e_{r}^{M S T} \lambda\right] / 8, \\
p^{M S T}=\left[3 a+2 b c+3\left(e_{d}^{M S T}+e_{r}^{M S T}\right) \lambda\right] / 8 b .
\end{gathered}
$$

Substituting Formulas (16) and (17) into the manufacturer's revenue $\prod_{m}^{M S}$, the Hessian matrix can be obtained as:

$$
H^{M S T}=\left|\begin{array}{cc}
\frac{\partial^{2} \prod_{m}^{M S T}}{\partial\left(e_{r}^{M S T}\right)^{2}} & \frac{\partial^{2} \prod_{m}^{M S T}}{\partial e_{r}^{M S T} \partial e_{d}^{M S T}} \\
\frac{\partial^{2} \prod_{m}^{M S T}}{\partial e_{d}^{M S T} \partial e_{r}^{M S T}} & \frac{\partial^{2} \prod_{m}^{M S T}}{\partial\left(e_{d}^{M S T}\right)^{2}}
\end{array}\right|=\frac{k\left[4(1-b) k-\lambda^{2}\right]}{4(1-b)}>0 .
$$

In addition, $\frac{\partial^{2} \prod_{m}^{M S T}}{\partial\left(e_{r}^{M S T}\right)^{2}}<0$. That is, the Hessian matrix $H^{M S T}$ is negative definite and has a maximum value. Let the two equations of $\partial \prod_{m}^{M S T} / \partial e_{r}^{M S T}=0$, $\partial \prod_{m}^{M S T} / \partial e_{d}^{M S T}=0$ be combined:

$e_{r}^{M S T^{*}}=e_{d}^{M S T^{*}}=[a-2(1-b) c] \lambda /\left[8(1-b) k-2 \lambda^{2}\right]$.

Substituting $e_{r}^{M S T^{*}}$ and $e_{d}^{M S T^{*}}$ into $w^{M S T^{*}}, q_{r}^{M S T^{*}}, q_{d}^{M S T^{*}}, p^{M S T^{*}}$, the optimal decisions are:

$$
\begin{gathered}
w^{M S T^{*}}=c+[a-2(1-b) c] k /\left[4(1-b) k-\lambda^{2}\right], \\
p^{M S T^{*}}=c+3[a-2(1-b) c] k /\left[8(1-b) k-2 \lambda^{2}\right], \\
q_{r}^{M S T^{*}}=-\frac{a}{2}(1-2 \theta)+(1-b)[a-2(1-b) c] k /\left[8(1-b) k-\lambda^{2}\right], \\
q_{d}^{M S T^{*}}=\frac{a}{8}(5-8 \theta)-\frac{(1-b) c}{4}+\frac{[a-2(1-b) c] \lambda^{2}}{8\left(4 b k-\lambda^{2}\right)} .
\end{gathered}
$$


The optimal benefits of retailer and manufacturer under manufacturer-led and unified pricing are:

$$
\prod_{r}^{M S T^{*}}=\frac{b[a-2(1-b) c]^{2} k^{2}}{2\left[4(1-b) k-\lambda^{2}\right]^{2}}, \quad \prod_{m}^{M S T^{*}}=\frac{[a-2(1-b) c]^{2} k}{4\left[4(1-b) k-\lambda^{2}\right]} .
$$

The total revenue of the supply chain is:

$$
\Pi_{c}^{M S T^{*}}=[a-2(1-b) c]^{2} k\left[6(1-b) k-\lambda^{2}\right] /\left[8(1-b) k-2 \lambda^{2}\right]^{2} .
$$

\subsubsection{Manufacturer Separate Pricing}

The same as the solution method in 3.2.1, we have the optimal decisions and benefits under manufacturer-led and separate pricing:

$$
\begin{aligned}
& e_{r}^{M S F^{*}}=e_{r}^{M S F^{*}}=[a-2(1-b) c] \lambda / 2\left[4(1-b) k-\lambda^{2}\right] \\
& w^{M S F^{*}}=\left[a k+c\left(2(1-b) k-\lambda^{2}\right)\right] / 4(1-b) k-\lambda^{2} \\
& \left\{\begin{array}{l}
q_{r}^{\text {MSF* }}=\frac{-2(1-b) k(2(1-b) c+a(1-4 \theta))+a(1-2 \theta) \lambda^{2}}{4\left[4(1-b) k-\lambda^{2}\right]} \\
q_{d}^{\text {MSF* }}=\frac{2(1-b) k(-2(1-b) c+a(3-4 \theta))-a(1-2 \theta) \lambda^{2}}{4\left[4(1-b) k-\lambda^{2}\right]}
\end{array}\right. \\
& \left\{\begin{array}{l}
p_{r}^{M S F^{*}}=\frac{1}{4}\left(\frac{4(1+b) c-a(1-2 \theta)}{1+b}+\frac{6[a-2(1-b) c] k}{4(1-b) k-\lambda^{2}}\right) \\
p_{d}^{M S F^{*}}=\frac{1}{4}\left(\frac{a+4(1+b) c-2 a \theta}{1+b}+\frac{6[a-2(1-b) c] k}{4(1-b) k-\lambda^{2}}\right)
\end{array}\right.
\end{aligned}
$$

The same as the solution method in 3.2.1, we have the optimal decisions and benefits under manufacturer-led and separate pricing:

$$
\left\{\begin{array}{l}
\Pi_{m}^{M S F^{*}}=(a-2(1-b) c)^{2} k /\left[4\left[4(1-b) k-\lambda^{2}\right]\right] \\
\prod_{r}^{M S F^{*}}=\frac{1}{8}\left(\frac{a^{2}(1-2 \theta)^{2}}{1+b}+\frac{4(1-b)(a-2(1-b) c)^{2} k^{2}}{\left[4(1-b) k-\lambda^{2}\right]^{2}}\right) .
\end{array}\right.
$$

The benefit of the supply chain is:

$$
\begin{aligned}
\prod_{c}^{M S F^{*}}= & \frac{4(1-b)\left[a^{2} k-2 c(a-(1-b) c)\left(6(1-b) k-\lambda^{2}\right)\right] k}{8\left[4(1-b) k-\lambda^{2}\right]^{2}} . \\
& +\frac{a^{2}(1-2 \theta)^{2}}{8(1+b)}+\frac{2 a^{2} k}{8\left[4(1-b) k-\lambda^{2}\right]}
\end{aligned} .
$$

\section{Comparative Analysis}

\subsection{Comparative Analysis under the Same Power Structure}

Under the leadership of retailer: $\prod_{r}^{R S F^{*}}>\prod_{r}^{R S T^{*}}, \prod_{m}^{R S F^{*}}=\prod_{m}^{R S T^{*}}, e_{r}^{R S F^{*}}=e_{r}^{R S T^{*}}$, 
$w^{R S F^{*}}=w^{R S T^{*}}, \quad q_{r}^{R S F}-q_{r}^{R S T}=a(1-2 \theta) / 4, \quad q_{d}^{R S F}-q_{d}^{R S T}=-a(1-2 \theta) / 4 ;$

$p_{r}^{R S F^{*}}-p^{R S T^{*}}=-a(1-2 \theta) /[4(1+b)], \quad p_{d}^{R S F^{*}}-p^{R S T^{*}}=a(1-2 \theta) /[4(1+b)]$.

Under the leadership of manufacture: $\prod_{r}^{M S F^{*}}>\prod_{r}^{M S T^{*}}, \prod_{m}^{M S F^{*}}=\prod_{m}^{M S T^{*}}$, $e_{r}^{M S F^{*}}=e_{d}^{M S T^{*}}, \quad w^{M S F^{*}}=w^{M S F^{*}}, \quad q_{r}^{M S F}-q_{r}^{M S T}=a(1-2 \theta) / 4$,

$q_{d}^{M S F}-q_{d}^{M S T}=-a(1-2 \theta) / 4 ; p_{r}^{M S F^{*}}-p^{M S T^{*}}=-a(1-2 \theta) /[4(1+b)]$, $p_{d}^{M S F^{*}}-p^{\text {MST* }}=a(1-2 \theta) /[4(1+b)]$.

Conclusion: Regardless of the power structure, the pricing method (uniform pricing and separate pricing) has no effect on the revenue of the manufacturer, while the retailer obtains higher revenue under separate pricing. In addition, the pricing method does not affect the manufacturer's setting of wholesale price, nor does it affect the level of carbon emission reduction. Consumers have a greater preference for which channel, and retailers will set a relatively higher price for that channel when pricing separately. When $\theta>0.5(\theta<0.5)$, the retail channel price under separate pricing is greater (less than) the sales price under uniform pricing, and the order quantity of retail channel under separate pricing is less than (greater than) the order quantity of retail channel under uniform pricing; The sales price of direct channels is less than (greater than) the sales price under uniform pricing, and the order quantity of direct channel under separate pricing is greater (less than) the order quantity of direct channel under uniform pricing. At that time, the sales prices of the two channels under separate pricing were the same as the sales prices under unified pricing, and the order quantities of the two channels were also the same as those under unified pricing.

\subsection{Comparative Analysis under Different Power Structures}

Proposition 1: Analysis of carbon emission reduction level:

$$
\begin{aligned}
e_{r}^{R S T^{*}}-e_{d}^{M S T^{*}} & =e_{r}^{R S F^{*}}-e_{d}^{M S F^{*}} \\
& =[a-2(1-b) c] \lambda^{3} /\left[32(1-b)^{2} k^{2}-24(1-b) k \lambda^{2}+4 \lambda^{4}\right] \\
& >0
\end{aligned}
$$

Proposition 1 shows that the level of carbon emission reduction led by retailers is better, and the greenness and environmental protection effect are better. This is because an increase in the level of carbon emission reduction will increase consumer demand, and retailers will encourage manufacturers to increase the level of carbon emission reduction in order to obtain more revenue, thereby increasing the degree of greenness.

Regardless of the pricing method, the level of carbon emission reduction is an increasing function of and. The higher the cost of investing in carbon emission reduction, the weaker the manufacturer's investment, so the level of carbon emission reduction will decrease. The higher consumers' low-carbon preference means that consumers are more willing to buy low-carbon products, and manufacturers will be more willing to increase their carbon emission reduction levels.

Proposition 2: Price comparative analysis: when $k \in\left(\frac{\lambda^{2}}{2(1-b)}, \frac{\lambda^{2}}{1-b}\right)$, then 


$$
\begin{aligned}
& p^{R S T^{*}}>p^{M S T^{*}}, \quad p_{r}^{R S T^{*}}>p_{r}^{M S T^{*}}, p_{d}^{R S T^{*}}>p_{d}^{M S T^{*}} \text {; when } k \in\left(\frac{\lambda^{2}}{1-b},+\infty\right) \text {, then } \\
& p^{R S T^{*}}<p^{M S T^{*}}, \quad p_{r}^{R S T^{*}}<p_{r}^{M S T^{*}}, p_{d}^{R S T^{*}}<p_{d}^{M S T^{*}} .
\end{aligned}
$$

Proposition 2 shows that when the carbon emission reduction cost coefficient is low (high), regardless of the pricing method, the retailer-led sales price is greater (less than) the manufacturer-led sales price.

In the case of unified pricing, the sales price is not affected by consumer channel preferences. In separate pricing, the retail channel price is an increasing function of consumer channel preferences, and the direct channel price is a decreasing function of. Explain which channel consumers prefer to buy goods, and retailer will set higher prices in the corresponding channels.

Proposition 3: Comparative analysis of order quantity. $q_{r}^{R S F}-q_{r}^{M S F}=q_{d}^{R S F}-q_{d}^{M S F}>0 ; q_{r}^{R S T}-q_{r}^{M S T}=q_{d}^{R S T}-q_{d}^{M S T}>0$.

Proposition 3 shows that no matter what the pricing method, the order quantity under the lead of the retailer is greater than the order quantity under the lead of the manufacturer. The main reason is that when retailers dominate, they will prompt manufacturers to increase carbon emission reduction levels, thereby increasing consumer demand for low-carbon products. And the order quantity is an increasing function of consumer channel preference $\theta$, and the decreasing function of carbon emission reduction cost investment coefficient $k$.

Proposition 4: Comparative analysis of wholesale prices: when

$k \in\left(\frac{\lambda^{2}}{2(1-b)}, \frac{3 \lambda^{2}}{4(1-b)}\right)$ then $w^{R S T^{*}}>w^{M S T^{*}}, w^{R S F^{*}}>w^{M S F^{*}}$; when $k \in\left(\frac{3 \lambda^{2}}{4(1-b)},+\infty\right)$, then $w^{R S T^{*}}<w^{M S T^{*}}, w^{R S F^{*}}<w^{M S F^{*}}$.

Proposition 4 shows that when the carbon emission reduction investment cost coefficient is small (large), the wholesale price led by the retailer is greater (less than) the wholesale price led by the manufacturer.

Regardless of the pricing method, the $w$ is a decreasing function of $k$ and an increasing function of $\lambda$. When the cost of investing in carbon emission reduction is high, the investment of manufacturers is greatly reduced. If the wholesale price is increased, the corresponding retailer will reduce the order quantity. Therefore, manufacturers will lower wholesale prices to encourage retailers to place more orders. The higher consumers' low-carbon preference means that consumers are more willing to buy low-carbon products, and manufacturers will raise wholesale prices to obtain more profits.

Proposition 5: Comparative analysis of the benefits of supply chain members. when $k \in\left(\frac{\lambda^{2}}{2(1-b)}, \frac{3 \lambda^{2}}{4(1-b)}\right)$ then $\prod_{m}^{R S T^{*}}>\prod_{m}^{M S T^{*}}, \prod_{m}^{R S F^{*}}>\prod_{m}^{M S F^{*}}$; when $k \in\left(\frac{3 \lambda^{2}}{4(1-b)},+\infty\right)$, then $\prod_{m}^{R S T^{*}}<\prod_{m}^{M S T^{*}}, \prod_{m}^{R S F^{*}}<\prod_{m}^{M S F^{*}} ;$ when 
$k \in\left(\frac{\lambda^{2}}{2(1-b)},+\infty\right)$ then $\prod_{r}^{R S T^{*}}>\prod_{r}^{M S T^{*}}, \prod_{r}^{R S F^{*}}>\prod_{r}^{M S F^{*}}$ and $\prod_{C}^{R S T^{*}}>\prod_{C}^{M S T^{*}}$, $\prod_{C}^{R S F^{*}}>\prod_{C}^{M S F^{*}}$.

Proposition 5 shows that from the perspective of the manufacturer, when the carbon emission reduction investment cost coefficient is small, the revenue under the leadership of the retailer is greater than that under the leadership of the manufacturer. When the carbon emission reduction investment cost coefficient is large, the income under the leadership of the retailer is less than the income under the leadership of the manufacturer. This is because when the carbon emission reduction cost coefficient is low and retailer dominate, in order to increase consumer demand for low-carbon products, retailer require manufacturers to increase their carbon emission reduction levels, but at the same time, retailer increase their ordering volume so that manufacturer in this case, the benefits are higher.

And when the carbon emission reduction cost coefficient is large and retailer dominate, retailer encourage manufacturers to increase their carbon emission reduction levels. Although retailers increase their orders, they are not enough to make up for the high cost of manufacturers investing in carbon emission reduction technologies. In this case, the manufacturer's profit is small.

From the retailer's point of view, regardless of the pricing method, the revenue under the leadership of the retailer is always greater than the revenue under the leadership of the manufacturer.

From the perspective of the overall revenue of the supply chain, regardless of the pricing method, the total revenue led by the retailer is always greater than the total revenue led by the manufacturer.

\section{Conclusion}

Considering the impact of different power structures and pricing methods on supply chain performance, four game models are constructed respectively for retailer in dual-channel unified pricing and separate pricing, as well as two power structures led by manufacturer and retailer. The optimal decisions and benefits of supply chain members under different power structures and different pricing methods were obtained and compared and analyzed. The study found that:

Under the same power structure, a retailer is more inclined to set different prices for direct channel and retail channel, that is, separate pricing methods. This is because there are consumer channel preferences, and retailer will set higher prices for channels that consumers prefer. When consumers do not have channel preference $(\theta=0.5)$, the selling price under uniform pricing is the same as the prices under the two channels under separate pricing. For the manufacturer, the pricing method does not affect their earnings, nor does it affect the carbon emission reduction level and the establishment of wholesale prices.

Under different power structures, it is more profitable for retailer to dominate 
themselves. For manufacturer, when the carbon emission reduction investment cost coefficient is small (large), the benefits are greater when the retailer (self) is dominant. The level of carbon emission reduction led by retailer is higher than the level of carbon emission reduction led by manufacturer. This shows that, compared with the manufacturer's leadership, the manufacturer will perform more environmental responsibilities under the leadership of the retailer.

This article focuses on the comparison of different pricing methods and different power structures to enrich the research of retailer's dual-channel low-carbon supply chain. The model in this paper can also be extended to consider the impact of pricing method and power structure on the performance of the supply chain under the asymmetry of information, which will continue to be improved in future work.

\section{Conflicts of Interest}

The author declares no conflicts of interest regarding the publication of this paper.

\section{References}

Chen, X., \& Wang, X. (2015). Free or Bundled: Channel Selection Decisions under Different Power Structures. Omega, 53, 11-20. https://doi.org/10.1016/j.omega.2014.11.008

Ji, J., Zhang, Z., \& Yang, L. (2017). Carbon Emission Reduction Decisions in the Retail-/Dual-Channel Supply Chain with Consumers' Preference. Journal of Cleaner Production, 141, 852-867. https://doi.org/10.1016/j.jclepro.2016.09.135

Jin, L. (2018). Pricing Policies and Offline to Online Channel Strategies under Different Supply Chain Power Structures. Journal of Systems Science and Mathematical Sciences, $38,946-959$.

Lan, T. (2018). The Impact of Different Supply Chain Power Structure for Optimal Pricing and Brand Differentiation Strategy. Soft Science, 32, 139-144.

Li, B., Zhu, M., Jiang, Y. et al. (2016). Pricing Policies of a Competitive Dual-Channel Green Supply Chain. Journal of Cleaner Production, 112, 2029-2042. https://doi.org/10.1016/j.jclepro.2015.05.017

Liang, X., Jiang, Q., \& Guo, J. (2018). Pricing Policy and Channel Selection of Manufacturers under Different Dual Channel Structure. Chinese Journal of Management Science, 26, 97-107.

Liu, M., Xu, Y., \& Fu, H. (2019). Low Carbon Supply Chain Decision-Making and Channel Cooperation under Dual Channel Background. Soft Science, 33, 105-111.

Luo, Z., Chen, X., \& Kai, M. (2018). The Effect of Customer Value and Power Structure on Retail Supply Chain Product Choice and Pricing Decisions. Omega, 77, 115-126. https://doi.org/10.1016/j.omega.2017.06.003

Ma, L. (2019). Thinking on China's Low-Carbon Economic Development. Cooperative Economy and Technology, No. 5, 36-37.

Ranjan, A., \& Jha, J. K. (2019). Pricing and Coordination Strategies of a Dual-Channel Supply Chain Considering Green Quality and Sales Effort. Journal of Cleaner Production, 218, 409-424. https://doi.org/10.1016/j.jclepro.2019.01.297 
Sun, J., \& Xiao, Z. (2018). Decision-Making of Dual-Channel Supply Chain Emission Reduction Based on Consumer Preference to Low-Carbon. Chinese Journal of Management Science, 26, 49-56.

Wang, W., Li, G., \& Cheng, T. C. E. (2016). Channel Selection in a Supply Chain with a Multi-Channel Retailer: The Role of Channel Operating Costs. International Journal of Production Economics, 173, 54-65. https://doi.org/10.1016/j.ijpe.2015.12.004

Wang, X., Sun, Z., \& Zhan, H. (2017). Impact of Different Game Power Structures on the Cross-Border e-Retailer Dual-Channel Retail Supply Chain. Journal of Systems Engineering, 32, 385-396.

Xu, J., Qi, Q., \& Bai, Q. (2018). Coordinating a Dual-Channel Supply Chain with Price Discount Contracts under Carbon Emission Capacity Regulation. Applied Mathematical Modelling, 56, 449-468. https://doi.org/10.1016/j.apm.2017.12.018

Yang, L., Wang, G., \& Ke, C. (2018). Remanufacturing and Promotion in Dual-Channel Supply Chains under Cap-and-Trade Regulation. Journal of Cleaner Production, 204, 939-957. https://doi.org/10.1016/j.jclepro.2018.08.297

Yang, S., \& Xiao, D. (2017). Channel Choice and Coordination of Two-Stage Low-Carbon Supply Chain. Soft Science, 31, 92-98.

Yang, Y., Cheng, Y., \& Chen, S. (2019). Stimulating Corporate Social Responsibility in Supply Chain in Different Dominated Modes. Chinese Journal of Management Science, 27, 144-156.

Yu, L., Shi, G., \& Chen, J. (2019). Pricing Strategy of Dual-Channel Supply Chain Based on Different Low-Carbon Preference. Statistics \& Decision, 35, 43-47.

Zhang, X., Wu, D., Wang, J. et al. (2018). Research on the Pricing Decision of Manufacturer Dual-Channel Supply Chain Considering Return Risk. Chinese Journal of Management Science, 26, 59-70.

Zhou, X. (2017). Research on Emission Reduction and Pricing Decision Making of Dual Channel Low-Carbonization Supply Chain. Mathematics in Practice and Theory, 47, 20-28. 